\title{
A Treatment Program for Social Anxiety Disorder by Using Virtual Reality
}

\author{
Yhann Hafael Trad Perandré ${ }^{1,2, *}$ \\ Orcid.org/0000-0002-4483-9612 \\ Verônica Bender Haydu ${ }^{2}$ \\ Orcid.org/0000-0002-4522-8338 \\ ${ }^{1}$ Universidade Federal do Paraná, Jandaia do Sul, PR, Brasil \\ ${ }^{2}$ Universidade Estadual de Londrina, Londrina, PR, Brasil
}

\begin{abstract}
Virtual Reality (VR) was used in this study as a therapeutic tool in a behavior-analytic intervention with two subjects who had social anxiety disorder. The goals were to assess the therapeutic effects of the intervention program and the VR simulator with regard to the ability to generate sense of presence and anxiety responses. The program consisted of: (a) initial session, (b) baseline, (c) intervention sessions with exposure to VR, (d) closing session, (e) follow up (up to one and three months after treatment). Sense of presence, anxiety and galvanic skin response were reported in each exposure therapy session and anxiety, depression and social phobia inventories were reported at the end of each stage. Functional analyses were formulated based on behaviors occurring in social contexts between sessions. The simulator produced anxiety and high levels of presence during exposure; and both participants had reduced levels of anxiety at the end of intervention and generalization to the natural context. In conclusion, behavior-analytic intervention with exposure to VR was effective and fostered a repertoire for coping with situations of social interaction.
\end{abstract}

Keywords: Virtual reality, social anxiety disorder, behavior-analytic therapy, sense of presence, galvanic skin response.

\section{Um Programa de Intervenção para Transtorno de Ansiedade Social com o Uso da Realidade Virtual}

\section{Resumo}

A Realidade Virtual (RV) foi utilizada nesse estudo como recurso terapêutico em uma intervenção analítico-comportamental para dois participantes com transtorno de ansiedade social. Os objetivos foram avaliar os efeitos terapêuticos do programa de intervenção e o simulador quanto à capacidade de gerar senso de presença e respostas de ansiedade. O programa consistiu em: (a) sessão inicial, (b) linha de base, (c) intervenção com exposição à RV, (d) encerramento e (e) follow up (1 e 3 meses após a

Mailing address: Universidade Federal do Paraná, Campus Jandaia do Sul, Rua Doutor João Maximiano, 426, Vila Operária, Jandaia do Sul, PR, Brazil 86900-000. Phone: (41) 3208-6190. E-mail: yhann.perandre@ hotmail.com

Verônica Bender Haydu é bolsista Produtividade em Pesquisa da Fundação Araucária. 
intervenção). O senso de presença, ansiedade e respostas galvânicas da pele foram registrados em cada sessão com exposição e inventários de ansiedade, depressão e fobia social ao término de cada fase. Foram formuladas análises funcionais baseadas na ocorrência de comportamentos apresentados em contexto social no intervalo entre as sessões. O simulador produziu ansiedade e níveis elevados de presença ao longo das exposições; e ambos participantes apresentaram redução dos níveis de ansiedade ao fim do programa e generalização para o contexto natural. Conclui-se que a intervenção com exposição à RV apresentou efeito terapêutico e promoveu repertório de enfrentamento frente a situações de interação social.

Palavras-chave: Realidade virtual, transtorno de ansiedade social, terapia analítico-comportamental, senso de presença, resposta galvânica da pele.

\section{Un Programa de Intervención para la Trastorno de Ansiedad Social con el Uso de la Realidad Virtual}

\section{Resumen}

La realidad virtual (RV) fue empleada en este estudio como herramienta terapéutica en un programa de intervención analítico-conductual para dos participantes con trastorno de ansiedad social. Los objetivos fueron evaluar los efectos terapéuticos del programa de intervención y el simulador en cuanto a la capacidad de generar presencia y respuestas de ansiedades. El programa consistió en: (a) sesión inicial, (b) línea base, (c) intervención con exposición a la RV, (d) finalización y (e) seguimiento (1 y 3 meses después de la intervención). La sensación de presencia, ansiedad y la respuesta galvánica de la pele fueron registrados en cada sesión con exposición y inventario de la ansiedad, depresión y fobia social al final de cada fase. Análisis funcionales fueron formulados en base a la ocurrencia de las conductas de interacción social en el intervalo entre las sesiones. El simulador produce ansiedad y niveles elevados de presencia a lo largo de las exposiciones y ambos participantes presentaron reducción de los niveles de ansiedad al final de lo programa, con generalización de los resultados para un contexto natural. Se concluye que la intervención analítico-conductual con la exposición a la RV tuvo efecto terapéutico y aprendieron un repertorio de afrontamiento de esas situaciones.

Palabras clave: Realidad virtual, trastorno de ansiedad social, terapia de la conducta, sensación de presencia, respuesta galvánica de la piel.

New technologies have been increasingly accepted and incorporated as a useful resource for Psychology, both in the scientific field and also in the provision of services such as psychology clinics. Using technological resources can contribute to the agility of the therapeutic process and to the development of increasingly creative and productive forms of action (Barbosa, 2013). As a complementary resource to psychotherapy, Virtual Reality (VR) technology enables dynamic and active ways of acting by both therapist and client, as well as opening space for systematic investigations as to the efficacy of therapeutic intervention programmes that include this technology.
Studies of therapy using VR have begun to gain force especially in the last two decades (e.g., Klinger et al., 2005; Price, Mehta, Tone, \& Anderson, 2011; Slater, Pertaub, Barker, \& Clark, 2006; Wallach, Safir, \& Bar-Zvi, 2011). In these studies, VR appeared as a resource that facilitates exposure techniques; as a controlled environment for the immersion of individuals with social anxiety disorder (social phobia); as well as enabling the shaping of social behaviors through programmed contingencies (e.g., Harris, Kemmerling, \& North, 2002; Morina, Brinkman, Hartanto, \& Emmelkamp, 2014; Price et al., 2011). As such, VR has become considered to be a new and promising tool that can be used 
in psychological interventions. Notwithstanding, questions are raised regarding: (a) VR effectiveness as a therapeutic resource when compared to other forms of treatment (e.g., Kampmann et al., 2016; Klinger et al., 2005), (b) the validity of intervention programs using VR as their main resource (e.g., Roy et al., 2003), and (c) the way in which specific phobias can be assessed through biofeedback (e.g., Wiederhold, Jang, Kim, \& Wiederhold, 2002) or through self-reporting, inventories and questionnaires (e.g., Harris et al., 2002).

One of the aspects to be considered in interventions using VR consists of the ability of the simulator to promote sense of presence, which can be defined as "the feeling of 'being there' in the virtual environment", which involves public and/or private responses evoked by discriminative stimuli and maintained by consequences produced by the environment (operant behaviors) and responses (public and/or private) elicited by stimuli from the virtual environment (respondent behaviors) (Zacarin et al., 2017, p. 259). Sense of presence is especially relevant in therapeutic techniques such as exposure and response prevention and systematic desensitization, since for VR to be used in these techniques the VR simulator needs to present a set of situations that provoke discomfort or anxiety. According to Qu, Brinkman, Ling, Wiggers and Heynderickx (2014), exposure to these situations can be programmed to occur gradually, slowly increasing the level of aversion, in keeping with the individual's tolerance.

Gradual exposure to feared stimuli can take place following adequate recognition of the phenomenon being treated. In a study proposed by Holt, Heimberg, Hope and Liebowitz (1992), social anxiety disorder was analyzed based on anxiety felt in different contexts. These authors proposed 24 distinct situations that could be summarized into four common situational domains: (a) formal speaking/interaction, (b) informal speaking/interaction, (c) being scrutinized, (d) assertiveness. The situational domains proposed by Holt et al. served as a basis for experimental studies of social anxiety and the concept was reintroduced by Klinger et al. (2005) and Roy et al. (2003) as: (a) performance anxiety (difficulty in carrying out activities in a social context, such as speaking in public), (b) intimacy anxiety (an individual's inability to start conversations, create and maintain bonds of affection), (c) scrutiny anxiety (difficulty in carrying out activities while being watched by others, such as using an automated teller machine or talking on the telephone in a crowded shopping center), (d) assertiveness anxiety (difficulty in expressing and stating one's opinion and position in relation to something and protecting one's interests). In a more recent study conducted by Heijden and Brinkman (2011), VR was used based on the concept of scrutiny anxiety, whereby some people spoke for several minutes to a virtual audience and were assessed by the quality of their spoken interaction. Characterizing this disorder based on situational domains emphasizes the contexts in which an individual may present an insufficient behavioral repertoire for coping with situations of social interaction.

Another characterization of social anxiety disorder takes it as a behavioral process and emphasizes the description of the disorder's maintaining variables based on the functional analysis of the behaviors shown by the individual (Leonardi, Borges, \& Cassas, 2012). This functional analysis as a behavioral analysis describing the diagnostic category of social anxiety disorder is done though the operationalization of the following aspects: (a) response classes on molar levels, (b) consequences, (c) events preceding the response, (d) reinforcement history, and (e) treatment derived from this functional assessment (Sturmey, 1996; Silvares \& Meyer, 2000). In a study reported by Rocha, Bolsoni-Silva and Verdu (2012), it was highlighted that individuals with social anxiety disorder can show shortcomings in social skills in a specific situational context but not in another, thus making evident the relevance of functional analysis.

In an analysis of social anxiety behavioral processes, Zamignani and Banaco (2005) identified that individuals may present certain behaviors such as tachycardia, alteration of galvanic skin response, hyperventilation, choking sensation, sweating, discomfort and shaking in the 
face of environmental stimuli gaining properties of elicitation through respondent conditioning processes (sounds and noises characteristic of large gatherings, for instance). At the same time, an individual can present operant behaviors maintained by negative reinforcement, such as escape, which interrupt the appearance of these stimuli (using earphones when crossing large centers, for instance) or avoidance in the case of stimuli preceding aversive stimulation (choosing alternative times to carry our everyday activities, for example). In some cases, successful avoidance may be maintained through positive reinforcement, such as permission not to take part in important meetings etc. Respondent and operant behaviors are therefore interrelated in a complete analysis of social anxiety disorder.

The objectives of behavioral therapy in the treatment of social anxiety disorder consist of reducing reflex responses, suppressing escape and avoidance, developing more reinforcing social relationships and social skills, and managing or coping with problems (Beidel et al., 2014; Nobile, Garcia, \& Bolsoni-Silva, 2017; Sampaio \& Bueno, 2011; Stevens, Peters, Abraham, \& Hermann, 2014). Sampaio and Bueno (2011) presented an intervention for fear of public speaking (specific social anxiety disorder) that consisted of arranging reinforcement contingencies so that the participant exposed herself to nonpunitive audiences and the level of audience aversiveness was then gradually increased. This procedure aimed to strengthen coping responses and weaken avoidance responses. At the end of the intervention, the study participant was capable of making a spoken presentation that ensured she was awarded an academic degree. According to the authors, the satisfactory result of the study was only possible because of the strategies applied. These included control of the environment together with the establishment of a hierarchy of events causing anxiety.

Lack of control of the natural environment can make exposure very aversive, leading to an avoidance response to the treatment condition itself (Anderson et al., 2013). Treatment programs using VR as a therapeutic tool, in turn, allow the control of some interaction contingen- cies between the user and the avatar (simulated character), which are useful in social anxiety disorder treatment programs. A recent study conducted by Roy et al. (2003) compared VR technology with social anxiety disorder therapies. An experimental group (G1) exposed to an intervention protocol of 12 sessions of VR was compared with another experimental group (G2) exposed to an intervention based on Cognitive Behavior Therapy (CBT) and to a third group (G3) that was not subject to an intervention (waiting list). In this experiment the three groups received post-test assessment and the average scores obtained by applying the Liebowitz Social Anxiety Scale were clearly reduced in the experimental groups (G1 and G2) in relation to $G 3$, with no statistical significance between G1 and G2. Similar results were found by other studies that also compared the effectiveness of VR and CBT in the treatment of social anxiety disorder (e.g., Klinger et al., 2005; Wallach, et al., 2011). These studies demonstrated that therapeutic effect can be found in interventions using VR, as well as in interventions using other therapies such as CBT. Notwithstanding, different results were obtained by Kampmann et al. (2016) in a randomized controlled clinical study which is summarized below.

Kampmann et al. (2016) compared the efficacy of a Virtual Reality Exposure Therapy (VRET) procedure with an In Vivo Exposure Therapy (IVET) procedure. Sixty participants diagnosed as having social anxiety disorder were randomly distributed between three groups, namely two treatment groups and one control group (waiting list). The VRET procedure was conducted in scenarios that enabled spoken interaction with virtual human beings (avatars) whilst the IVET procedure was conducted in real-life situations similar to the virtual ones. Both procedures were conducted in individual therapy. When the results of the groups that received treatment were compared by analyzing the assessments done before and after the interventions, both were found to have reduced avoidance behaviors, increased duration of speaking interactions and reduced perceived stress, when compared to the waiting list group. 
The participants who received IVET, but not those who received VRET, improved regarding fear of being negatively assessed, speaking performance, reduced overall anxiety and depression in relation to those on the waiting list. The authors concluded that VRET can reduce complaints of generalized social anxiety disorder and that "future improvements in technologies and virtual psychological social interactions may increase even more the efficacy of VRET in cases of social anxiety disorder" (p. 147).

The studies described above have demonstrated that treatments using VR can be effective. Their results were obtained through tests, inventories and self-reporting questionnaires, and physiological measurements, such as heart rate and skin conductance responses. A study conducted by Wiederhold et al. (2002) assessed the use of physiological measurements as an indicator of clinical improvement among participants who were afraid of flying and who underwent a procedure using VR. Heart rate, galvanic skin response and body temperature of 22 nonphobic participants and 36 phobic participants were monitored over six sessions of exposure to VR. The authors reported significant difference between the galvanic skin response measurements of phobic and non-phobic participants during exposure to VR. The physiological measurements returned to baseline levels among the non-phobic participants, whilst they remained at higher levels for longer among the phobic participants. At the end of the intervention, 33 of the 36 phobic participants showed clinical improvement (91.6\% success rate). However, assessment of the galvanic response was done based on group averages. A more faithful assessment measurement could consist of comparing each individual's own data over the sessions.

Based on investigations into the use of VR technology applied to the context of clinical interventions (Barbosa, 2013; Kampmann et al. 2016; Morina et al., 2014; Wallach et al., 2011; Wiederhold et al., 2002), our study had the following objectives: (a) to assess the effects of a behavior-analytic intervention program using VR to treat individuals with social anxiety disorder; (b) to assess a VR simulator designed for so- cial anxiety disorder regarding its ability to generate sense of presence and anxiety responses through biofeedback measurement of galvanic skin response and also through Subjective Units of Distress Scale - SUDS (Wolpe, 1973/1978).

\section{Method}

\section{Participants}

The study participants were two male university students aged 20 and 27 , referred to as P1 e P2, respectively. The participants were selected based on a semi-structured interview including the application of the BDI, BAI and SPIN tests, with the aim of verifying whether: (a) they met the requirements for psychological diagnosis of social anxiety disorder, based on DSM-5 criteria (American Psychiatric Association [APA], 2013); (b) they did not have any hypothetical diagnosis of depression or comorbidity; (c) they were not having psychological or pharmacological treatment at the same time as the study; and (d) they had time available to take part in the sessions twice a week for approximately one hour. The participants signed a Free and Informed Consent Form that had been approved by a Research Ethics Committee.

Participant $1(\mathrm{P} 1)$ was 20 years old, single (he was dating) university student. He had been living with his brothers since he began studying when he was 17 . Until then he had lived with his parents in a small inner-state town. He reported not being close to his parents and brothers, stating that he perceived them as "authorities, on a higher hierarchical position". During any spoken interaction with them he avoided eye contact and as a consequence these interactions were sporadic and brief. As a result, he was interpreted as being "shorttempered, high-strung" and as an emotional subproduct he felt sad. The same pattern repeated itself with teachers, other relatives, his music teacher (he had keyboard and singing lessons). He felt "fear of his fellow students, especially the more important and popular". P1 reported fear of speaking in seminars and his academic and artistic presentations were preceded by considerable anxiety. In the same way as 
happened in his presentations, all his spoken interaction was marked by tachycardia, loss of voice, shaking, fear, freezing, he felt insecure, reported low self-esteem and avoided situations.

P2 was a 27 year-old single (he was dating) university student. He shared a house with two other people, with whom he had no close contact. Prior to this he had lived with his mother in the state capital. He reported that it had taken him three years more than expected to finish high school. He had moved from one town to another and changed schools many times during his school years and felt particular difficulty with social interaction in those environments. He felt very uncomfortable going into and remaining in classrooms, because of the imminent interaction with his fellow students, having to talk about himself and about everyday subjects. This type of interaction made him feel shaky, go red, his legs wobbled and he felt anxiety. He had undergone psychotherapy several times since he was 16 years-old - the last time was a few years ago - with the aim of treating his social anxiety disorder, but without success. In addition, $\mathrm{He}$ felt difficulty in going to and remaining in restaurants, handling cutlery and eating in front of other people. P2 had a restricted behavioral repertoire and reported living a "routine": he went to his university every day, but on arriving at the classroom he would go somewhere else, like the university courtyard, libraries or any place where he would be unlikely to have to interact with his fellow students. Low attendance at lessons produced emotional sub-products such as "feelings of guilt and anger".

\section{Place and Materials}

The sessions were held in a room of the Psychology Clinic of a public university. The room had two chairs and a table for the material and equipment needed for the sessions.

The Mindfield ${ }^{\circledR}$ eSense Skin Response biofeedback device was used to monitor galvanic skin response (see https://goo.gl/kCidld) and the Vitua.Therapy ${ }^{\circledR}$ VR simulator - comprised of one Oculus Rift ${ }^{\circledR}$, two laptop computers, one Razer ${ }^{\circledR}$ Hydra joystick with two controls, as well as external earphones. The simulator showed specific scenarios designed for the treatment of social anxiety disorder. The scenarios shown had contexts for possible social interactions by the participant with avatars and possible performance of predetermined tasks. The scenarios were designed to follow a sequence of events, although nothing prevented them from being shown in an alternative order. The first scene consisted of a shopping center food court without any avatars; with effect from the second scene avatars were gradually introduced. The second scene consisted of an automated teller machine that could be operated, located in a food court; the third scene took place in one of the food court snack bars; the fourth and fifth scenes happened in part of the same food court where there were tables and chairs.

\section{Instruments}

The instruments specified as follows were used to measure behaviors. The Subjective Units of Distress Scale - SUDS; (Wolpe, 1973/1978) indicated the level of anxiety and discomfort felt during exposure to VR using scores varying between 0 and 10. Scores closer to 0 indicated no level of anxiety whilst scores closer to 10 indicated higher levels of anxiety.

The Sense of Presence Inventory (SPI) consisted of 14 items describing exposure to VR in terms of virtual stimuli, real-life stimuli, physiological reactions during exposure and behavior shown throughout exposure. Answers were given according to a Likert scale from 0 (totally disagree) to 4 (totally agree). The total score showed the extent to which the participants felt themselves to be present in the virtual environment.

The Beck Anxiety Inventory - BAI (Cunha, 2001) assessed the frequency of the occurrence of behaviors compatible with anxiety disorder. BAI was comprised of 21 items using a Likert scale of 0 to 3. A total score of 0 to 10 corresponded to the Minimum level; 11 to 19, Mild; 20 to 30 , Moderate; 31 to 63 , Severe.

The Beck Depression Inventory - BDI (Cunha, 2001) assessed the frequency of the oc- 
currence of behaviors compatible with depression. BDI was comprised of 21 items using a Likert scale of 0 to 3 . A total score of 0 to 11 corresponded to the Minimum level; 12 to 19 , Mild; 20 to 35, Moderate; 36 to 63, Severe.

The Social Phobia Inventory-SPIN (Osório, Crippa, \& Loureiro, 2009) assessed the frequency of the occurrence of behaviors compatible with social phobia. SPIN was comprised of 17 items using a Likert scale from 0 to 4 and a total score of greater than 19 indicated the presence of these symptoms.

The Behavior Recording Chart consisted of a sheet of paper on which the participant reported social interaction situations that he had faced or avoided between one session and the next, so as to enable functional analyses and verify whether the intervention could be generalized to other contexts.

Apart from these instruments, the VR Exposure Instruction Sheet was also used. This: (a) provided a short explanation of behaviors involved in interpersonal relationships that produced fear and/or avoidance of situations, (b) assisted understanding of behavioral relationships enabled through exposure to VR, and (c) described the objectives of exposure to VR.

\section{Procedure}

The program was comprised of one initial session; five baseline sessions; eight intervention sessions with exposure to VR; one closing session; two follow-up sessions, one of which occurred one month after the closing session and the other three months after the closing session. The number of sessions in each stage of the procedure served as a reference and was sensitive to the needs of each participant. For both participants, the initial session and the closing session were conducted in two stages, given that the application of the tests and inventories also took place in them.

Initial Session. The initial session consisted of a semi-structured interview followed by a presentation of the study, its objectives and procedures. Participation was recorded through the signing of a Free and Informed Consent Form and only after this were the BDI, BAI and SPIN tests applied.

Baseline Stage. The baseline was comprised of five sessions. The sensors of the biofeedback device were placed on the participant's fingers and the device was switched on 40 seconds prior to starting to use the Virtua. Therapy simulator. In all baseline sessions the participant was exposed to Scene 1, this being a scenario that did not require social interactions, with the aim of teaching the participant how to use the equipment and accessories, such as the joysticks, the "get objects" function, moving and head-tracking. The instruction given to the participant was to

explore the scenario and its areas, for the time you think is needed to learn to use the equipment and become familiarized with the technology. At the beginning, avoid sudden head movements, as you may experience discomfort, such as dizziness.

Exposure was programmed to last for five minutes and could finish before this at the participant's request.

Once exposure had ended, the biofeedback device remained switched on for a further 40 seconds to enable stabilization of the data collected. The participant answered the SUDS and SPI instruments immediately following exposure to VR, as well as being sounded with the aim of investigating their experience with the simulator and accessories. The participant was asked "What did you feel?", "How did you act to deal with this?", "Is there anything you believe it is important to comment on?" The same procedure occurred in all the baseline sessions.

Intervention Stage. During the intervention stage, apart from exposure to VR, other therapeutic resources were introduced: diaphragmatic breathing, functional analysis of behaviors done using the Recording Chart. These resources comprised the intervention program. The participant was taught diaphragmatic breathing during the first session of the intervention stage. This consisted of explaining how to use the diaphragm muscle when breathing, facilitating the entry of air into the lungs and greater oxygen- 
ation with less effort. To this end the instruction was given to:

concentrate on your breathing, try and feel the breathing in and breathing out movements, try to make them increasingly slower, feel the air entering your mouth, and then leaving it, pay attention to your stomach, it swells when you breath in, bringing the air in, and then shrinks when you breath out. Try to notice how relaxing it is to pay attention to your breathing, and just how much you have control over it, feel your entire body contributing to your breathing, relaxing, concentrate on this sensation of pleasure.

The VR exposure intervention procedure consisted of: (a) rapport; (b) functional analysis of the Behavior Recording Chart; (c) diaphragmatic breathing; (d) exposure to VR; (e) application of the SUDS and SPI instruments; and (f) evaluation of the experience with the simulator and accessories. In the same way as during the baseline stage, the biofeedback device was switched on 40 seconds before exposure to VR and switched off 40 seconds after exposure had ended.

The exposure scenarios simulated social interactions and the performance of activities in a simulated social context. The scenes were divided into exposures capable of producing scrutiny anxiety (Scene 2), assertiveness anxiety (Scene 3 ), performance anxiety (Scene 4) intimacy anxiety (Scene 5). The order of the scenarios was adjusted based on what had been reported in the initial session, according to the degree of progressive difficulty in dealing with situations. The same sequence was used for both participants. Exposure to VR could be interrupted at any time by the participant or researcher if the participant showed signs of not feeling well (nausea, headache, dizziness, for example), if exposure was more aversive than the participant was able to stand or for other reasons presented by the participant. However, interruption was not necessary during the intervention.

After the biofeedback device had been switched off, the participant answered the SUDS and SPI instruments and then the experience of exposure to VR was evaluated. This evaluation consisted of an oral investigation, using questions of the following nature: "How did you feel during exposure?" and "What did you do afterwards and how did you feel about this?" The aim of this evaluation was to summarize, when the session was being brought to a close, behaviors shown by the participant during the session, antecedent and consequent conditions (i.e., to structure possible functional analyses within the context of exposure and during the session).

Closing Session. The BDI, BAI and SPIN post-intervention tests were applied during the closing session.

Follow-Up Sessions. These were held one and three months after the last session involving VR. In these sessions the participant was exposed once again to the VR scenarios, preceded by the diaphragmatic breathing exercise and with monitoring of the galvanic skin response. At the end the participant answered the BDI, BAI and SPIN tests again.

\section{Results}

The Behavior Recording Chart was presented during the first intervention session and the participants were instructed to fill it in between one session and the next, with the aim of providing input for the formulation of functional analyses in the following sessions with the participant. From the second intervention session up to the final follow-up session, P1 delivered nine completed Recording Charts with 4, 4, 1, 2, 3, 4, 2, 4 and 4 behavioral episodes, respectively. P2 handed in two completed charts with one behavioral episode described on each one.

The behavioral episodes reported by $\mathrm{P} 1$ on the Recording Charts occurred, for the most part, in a context of intimacy and in the performance of activities in a social context. The situations that P1 reported most frequently were doing presentations of assignments in the classroom, spoken interactions with fellow students and family members, as well as spoken interactions 
about his sexual orientation. In the episodes described on Charts 1, 2 and 3, which described conversations with friends about sexual orientation, antecedents were found to be: conversation circles and walks in the university courtyard. P1 reported that on these occasions, despite having thought about revealing his sexual orientation to his friends, he did not do so. He reported having changed the subject to issues other than his sexuality. The consequences observed were: (a) relief for not having exposed himself to his colleagues (avoidance function); (b) feeling of low self-esteem, shown by the following account: "I felt bad for not having been able to answer correctly [the questions about his sexual orientation] and for getting on edge".

In the behavioral episodes that described situations in an academic setting, such as questions asked of teachers, presenting assignments and seminars, P1 reported different answer classes as the intervention process developed. With regard to questions in the classroom, on the first charts P1 reported that he only asked questions when his colleagues were talking to each other. The consequence was relief in avoiding interaction with the other people present in that situation (avoidance). Nevertheless, this behavior pattern was detrimental to $\mathrm{P} 1$ when it was not possible to ask questions without being scrutinized by other people. By the end of the intervention period, the descriptions of the occasions when P1 interacted with the teacher also included the presence of his fellow students. P1 reported feeling happy for having managed to expose himself and that he frequently received adequate answers from the teacher (a reinforcing consequence for the behavior of asking questions in the classroom).

Other descriptions, on Charts 4, 6 and 7, presented situations of social interaction with family members. P1 faced up to the interaction situations and reported on Chart 4: "I was pleased that I managed to take part in the conversation and not just remain in silence"; Chart 6: "the conversation ended well. He [uncle] was pleased that I had spoken a little, including about his son"; Chart 7: "they [cousins and brothers] looked at me and laughed and I felt rather em- barrassed. I stopped laughing, but even so it was good". An increase in the frequency of the behavior of social interaction with family members can be seen after the intervention started, when compared to the frequency reported in the initial interview, and the behaviors shown were seen to be strengthened by the situation of interaction with family members.

P2 showed little commitment to the task of filling in the Recording Charts. On Chart 1, P2 gave an account of meeting his girlfriend's friends on a bus. P2 described not having interacted in keeping with the context, only speaking when spoken to, he felt "embarrassed" and stated "I did not give her [girlfriend] friends a good impression of myself'. P2 felt "uncomfortable" because of having few social skills. On Chart 2, P2 reported that in view of the need to get some information about the course he was taking, he went to the secretary's office. $\mathrm{He}$ experienced tachycardia and sweating. He asked his questions but did not get satisfactory answers. He felt "frustrated and annoyed" for not having been able to deal with the situation adequately. Generally speaking, at the beginning of the intervention, $\mathrm{P} 2$ had a restricted behavioral repertoire which was insufficient for social interactions. Based on spoken accounts, as the intervention sessions progressed P2's behavioral repertoire became more adaptable. Near to the end of the procedure, $\mathrm{P} 2$ reported having gone to social events where he interacted verbally with other guests and with friends of his girlfriend.

The results obtained from SPI, SUDS and biofeedback device, in each session involving exposure to VR, are shown in Figure 1. P1's data are shown in the upper part of the figure and P2's data are shown in the lower part, using a scale from 0 to 10 . The SPI scores were calculated by adding together the scores of each item and were then adjusted to this scale. The SUDS score did not need to be adjusted. The biofeedback measurement is shown as percentage variation of the galvanic skin response $(\% \Delta \mu \mathrm{S})$, adjusted to the scale of 0 to 10 . The vertical dotted lines after Sessions 5 and 13 indicate, respectively, the beginning and the end of the intervention. 

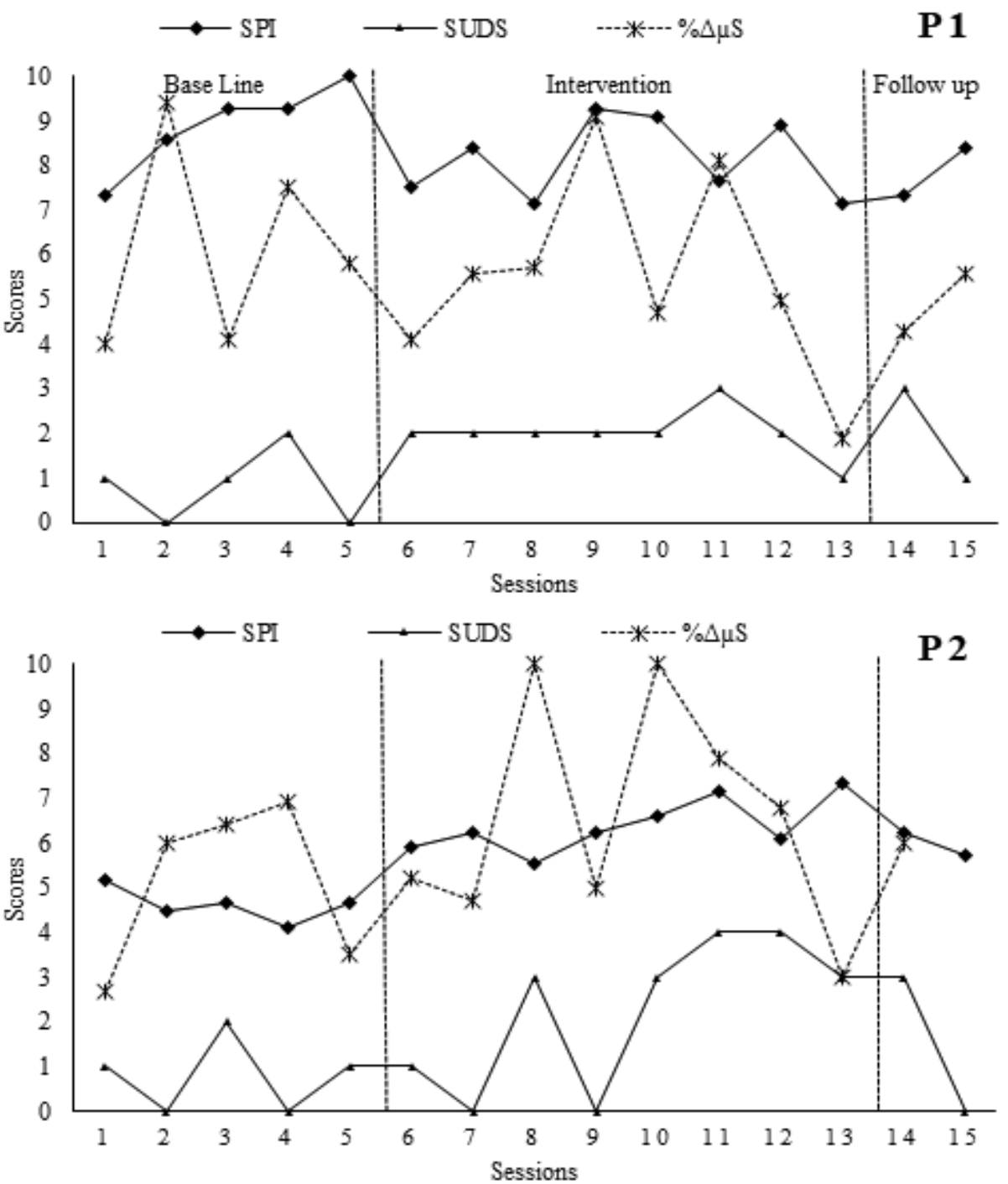

Figure 1. Distribution of scores corrected to a scale of 0 to 10 for SPI, SUDS and percentage variation of galvanic response, in 15 sessions of exposure to $V R$, for $P 1$ (upper part) and $\mathrm{P} 2$ (lower part). The galvanic response variation measurement of P2's last follow-up session was not recorded owing to equipment failure.

In Figure 1 the scores obtained using SUDS can be seen to vary between 0 and 3 for P1 and between 0 and 4 for P2 over the 15 sessions. SUDS was administered at the end of exposure and scores close to zero indicate a low level of anxiety having been felt. P1 varied between 0 and 3 only in the baseline sessions. After this point, the minimum measurement found was 1 (last intervention session), whilst in most of the sessions the measurement was 2. In P2's case, SUDS varied more (0 to 4$)$ and was more irregular than $\mathrm{P} 1$, varying from one session to another in the majority of cases. Figure 1 also shows high variability in the data on galvanic skin response variation (measured in microsie- mens $-\mu S$ ), for both $\mathrm{P} 1$ and $\mathrm{P} 2$, in all stages of the study (baseline, intervention and follow-up). $\mathrm{P} 1$ varied between 2 and 9 whilst P2 varied between 3 and 10. P2 showed a slight increase after the intervention stage started and in some sessions alterations in the score of the measurement reached 10 (Sessions 8 and 10). The sessions in which P2 had high measurement alterations coincided with the sessions in which the scenarios were changed (Sessions 6, 8, 10 and 12). In P1's case, there was no difference in the alterations in the measurements between the stages of the procedure and the sessions in which there were high measurement alterations (Sessions 2, 9 and 11) did not coincide with the scenario changes. 
Data recorded via SPI application showed less variation when compared to the other measurements ( 7 to 10 for $\mathrm{P} 1$ and 4 to 7 for P2). Differently to P1, who did not have variability between the stages of the procedure (he varied between 7 and 10 points in each stage), P2's SPI variation was different between the baseline sessions (4 and 5) and also for the intervention and follow-up sessions (6 and 7). SPI data both for P1 and for P2 showed 3-point amplitude on the scale. There was no apparent correspondence between SPI data and SUDS and biofeedback data, for both $\mathrm{P} 1$ and $\mathrm{P} 2$.

Figure 2 shows the scores obtained for the SPIN, BDI and BAI inventories which were applied five times to P1 (upper part of the figure) and P2 (lower part of the figure). SPIN scores above 19 indicate the presence of symptoms compatible with social anxiety disorder, whilst BDI and BAI scores above 20 indicate the possibility of depression and anxiety, respectively, at moderate levels.
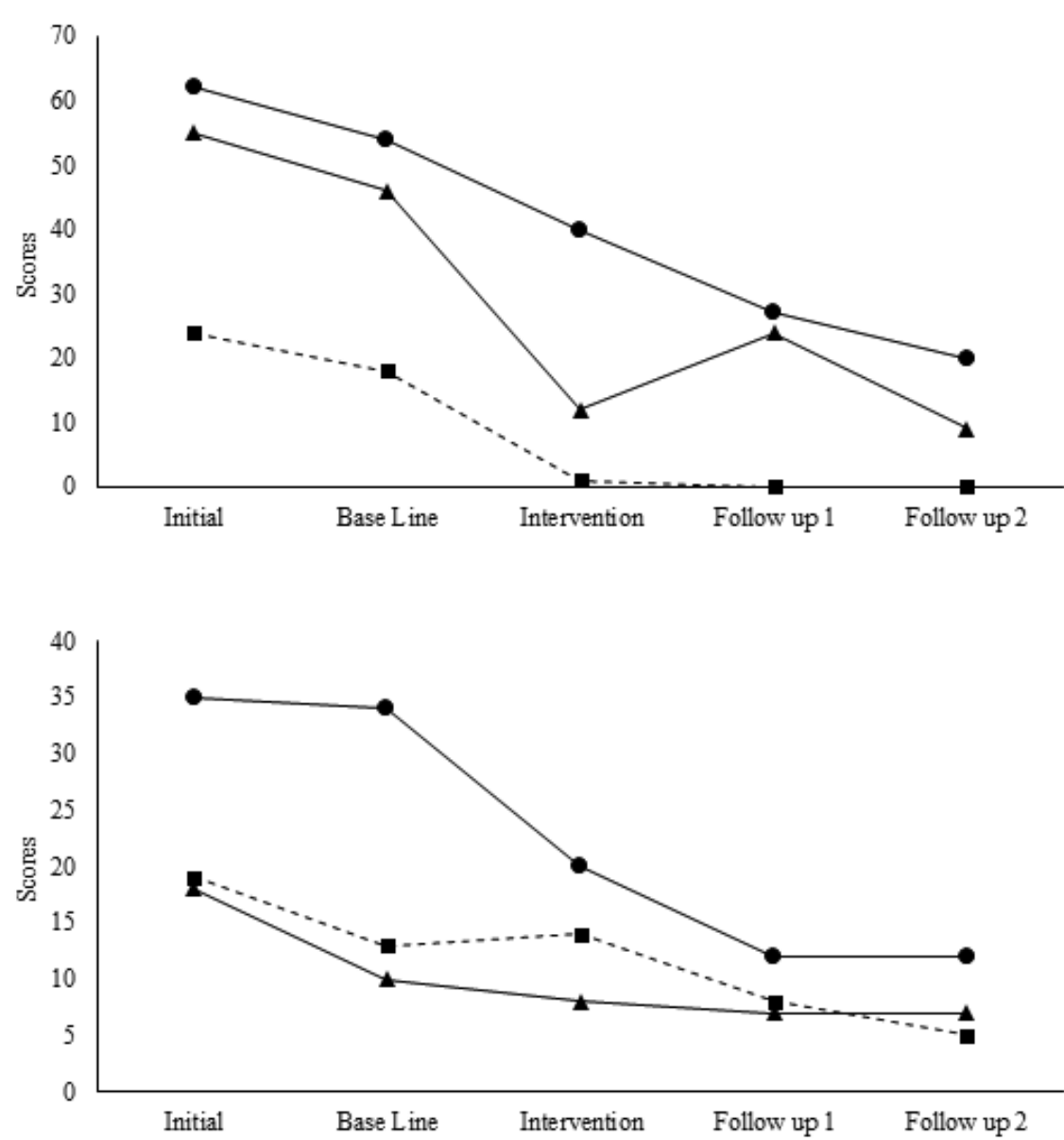

Figure 2. SPIN, BDI e BAI test scores after being applied five times to P1 and P2. Test application occurred in the initial session, at the end of the baseline, at the end of the intervention and in the $1^{\text {st }}$ and $2^{\text {nd }}$ follow-up sessions.
It can be seen in Figure 2 that as the application of the SPIN, BDI and BAI inventories progressed, the scores obtained by $\mathrm{P} 1$ and $\mathrm{P} 2$ decreased gradually in most of the applications. The scores for the three inventories decreased in the final application (Follow-up 2) in relation to the initial score in both cases. The SPIN, BDI
P 1

P2



and BAI score reductions between the first time (initial session) and the last time (Follow-up 2) they were applied were $68 \%, 100 \%$ and $84 \%$, respectively, for $\mathrm{P} 1$ and $66 \%, 74 \%$ and $61 \%$, respectively for $\mathrm{P} 2$. The scores obtained by $\mathrm{P} 1$ and $\mathrm{P} 2$ the last time the BDI and BAI inventories were applied decreased to the range indicating 
minimum symptoms (Cunha, 2001). The SPIN score obtained the last time this inventory was applied indicated the presence of social anxiety disorder symptoms in P1 (20), despite being close to the minimum score (19), whilst P2's score decreased to the minimum (7).

\section{Discussion}

The effects of the intervention program conducted using exposure to VR as a therapeutic resource will be discussed in order to verify behavioral changes related to the internal and external validity of the intervention. Internal validity, taken to be behavioral change observed during the intervention, was verified through the measurement instruments used before and after the intervention (SPIN, BDI and BAI). External validity, perceived as the quality of change beyond the research and intervention environment (Del Prette \& Del Prette, 2008), was verified in the accounts given in the sessions and on the $\mathrm{Be}$ havior Recording Charts about the behaviors of the participants in current social contexts.

The behaviors reported by $\mathrm{P} 1$ and $\mathrm{P} 2$ during the initial session and at baseline can be interpreted as being in the diagnostic category of social anxiety disorder, as described by Rocha, Bolsoni-Silva and Verdu (2012) and Zamignani and Banaco (2005), both from the history of acquisition of the behavioral repertoire and also from the history of its maintenance. Participants P1 and P2 showed great difficulty in facing up to and remaining in activities in social contexts, starting and maintaining dialogues with other people, engaging in intimate interactions and forming ties, frequenting public places, taking part in meetings, forming bonds of affection with other people. The contexts were generally under the scrutiny of other people, situations of performing activities in public, situations of spoken intimate interaction and situations in which assertive behavior was required.

With regard to the degree of familiarity with technical resources, Barbosa (2013) and Zacarin et al. (2017) argue that this aspect of exposure is an important variable for promoting sense of presence felt by an individual exposed to VR and that high levels of sense of presence are requisites for better treatment results. In this study the Sense of Presence Inventory (SPI) was applied at the end of each exposure and high levels of presence were found for $\mathrm{P} 1$, in the 15 exposure sessions, with the same variation over the study. P2 showed slight variation between the stages of the study. In general, P2 described less presence than P1 throughout the entire study. However, $\mathrm{P} 2$ reported a gradual increase in presence from the beginning of the intervention sessions and reached levels reported by P1. According to Barbosa (2013), environments requiring a larger number of actions by the immersed individual can produce higher levels of presence. This fact was seen in this study, whereby one of the changes occurring between baseline and intervention is characterized by an increase in environmental stimuli (in general, these are aversive stimuli for an individual with social anxiety disorder, such as a gathering of avatars having spoken interaction between themselves and with the participant) and an increase in interactive resources. In the intervention stage, P1 and P2 altered the environment significantly through the way in which they interacted with the simulator, this being a possible indicator of increased sense of presence in $\mathrm{P} 2$ in comparison with the baseline.

Taking the SPI results found for P1 and P2, it was not possible to establish a relationship with the SUDS and biofeedback results. Both P1 and $\mathrm{P} 2$ were exposed to the same sequence of scenarios in the intervention stage, but the way in which the participants responded to the SUDS requests were not similar to the changes in their galvanic skin response measurements. These findings suggest that: (a) this measurement of galvanic skin response may not adequately reflect states of anxiety (verified through SUDS) or (b) uncontrolled variables interfered with the measurements (lack of control of ambient temperature, for instance, which could interfere with galvanic skin response); and (c) the level of sense of presence reported may not be related to the level of anxiety. Findings in studies in the biography relating to positive correlation between sense of presence and measurements of anxiety 
(see Hartanto et al., 2014; Morina et al., 2014; Powers et al., 2013; Price et al., 2011) contradict the third hypothesis mentioned above.

The data relating to galvanic skin response measurement, obtained through percentage variation over the sessions with exposure to VR (Figure 1), indicated that both $\mathrm{P} 1$ and $\mathrm{P} 2$ 's galvanic response measurements altered during each session by at least $20 \%$ ( 2 points on the scale in question) in $\mathrm{P} 1$ 's case (13 $3^{\text {th }}$ session) and $30 \%$ ( 3 points on the scale) in P2's case $\left(1^{\text {st }}\right.$ and $13^{\text {th }}$ sessions). The changes in these measurements indicated that the scenarios produced alterations in the records of the participants' physiological levels during exposure and therefore meet the criterion discussed by Owens and Beidel (2015) for intervention effectiveness. Nevertheless, the alterations in the galvanic skin response did not show patterns that could be related to the scenario changes which, generally, included the addition of new and potentially anxiogenic stimuli, such as new avatars in the environment, programmed spoken interactions and performance of tasks under the scrutiny of other avatars.

The results obtained from applying SPIN, BDI and BAI (Figure 2) indicate, however, considerable changes during the procedure. According to criteria described by Cunha (2001), the scores obtained by P1 and P2 the first time BAI was applied (55 and 18, respectively) and the first time BDI was applied (24 and 18, respectively) indicate severe anxiety for P1 and mild anxiety for P2, as well as moderate depression for P1 and mild depression for P2. The scores obtained the last time the two inventories were applied indicate minimum states of anxiety and depression. The score reduction between the first and last application of the anxiety inventory was $84 \%$ in P1's case and $61 \%$ in P2's case. It should be emphasized that the tests applied covered a time period of one week. When verifying the items contained in BAI, it can be seen that what is treated as symptoms of anxiety also correspond to what Zamignani and Banaco (2005) describe as respondent behaviors of a behavioral repertoire characteristic of anxiety: shaking legs, nervousness, difficulty in breathing, sweating, palpitation, among others.
The results of the SPIN inventory also show considerable change during the procedure. Between the first time SPIN was applied (score of 62 for P1 and 35 for P2) and the last time it was applied (score of 20 for $\mathrm{P} 1$ and 12 for P2) a decrease of $68 \%$ and $62 \%$ was seen (P1 and $\mathrm{P} 2$, respectively). According to the descriptive analysis of the diagnostic category of social anxiety disorder proposed by Silvares and Meyer (2000) and according to the analysis of the behavioral processes involved in anxiety (Zamignani \& Banaco, 2005), the behaviors found by SPIN can be analyzed as operant behavior of a repertoire characteristic of anxiety (for instance, avoiding going to parties, avoiding speaking to people one does not know, avoiding speaking to any authority, among others). However, it should be emphasized that when performing adequate functional analysis, based on the behavior-analytic approach, other events apart from responses should be considered, such as the occasion on which the response occurs and the consequences of responding, as well as the establishing operations that momentarily determine events as reinforcements.

Taking the records obtained from the Behavior Recording Chart and unsystematic records of oral accounts given during the sessions, changes could be seen in behavior patterns of approaching situations that previously were avoided or endured with considerable suffering. During the last follow-up session, P2 reported that he had begun working for a company as a call-center operator and described it as a dynamic environment in workstations. He described his job duties as having to answer telephone calls from the company's customers in order to solve a variety of problems. From his brief account, it can be seen that his work was carried out in a highly social context. According to P2's description, his work colleagues invited him to a happy hour and, despite having felt "butterflies in his stomach", he accepted the invitation. P2 found the social event "pleasant and good fun", and mentioned that his colleagues had commented on the importance of repeating the event in the near future. When the intervention began, P2 was seen to have low frequency of leisure activities 
in social contexts. The behavioral episode reported illustrates social competencies developed over the course of the treatment process (such as assertiveness, starting conversations and keeping them going, maintaining ties and intimacy) as well as the reinforcement obtained through social interaction itself (such as such approval, feeling pleasure, "well-being").

Social competencies can also be seen in P1, with generalization to the natural context, as can be verified in an account provided by $\mathrm{P} 1$ on one of the Behavior Recording Charts. P1 reported that once when he was on his way to the Psychology Clinic, by chance he met a classroom colleague who was also going there. In view of the situation, P1 began a brief interaction and, despite having "become tense and almost breathless", he managed to maintain the dialogue, telling his colleague about how his own treatment was going. As a consequence, P1 stated that he felt "proud of himself" and reported emotional sub-products of happiness for having faced up to the situation. P1 found this interaction pleasant and the consequence was social approval by his colleague and company on the way to the Psychology Clinic, both of these being positive reinforcement for further behaviors of starting conversations, maintaining ties and intimacy. These results corroborate the external validity of the procedure by demonstrating that competencies developed by using exposure to VR were generalized outside of the clinically controlled environment.

During the course of the procedure, uncontrolled variables were encountered which may have interfered with the results relating to: (a) sense of presence, (b) galvanic skin response. We suggest that new studies be performed regarding environmental variables capable of interfering with measurements, such as ambient temperature and relative humidity of the air, hormonal issues, lack of sleep and food, expectations as to results. Other aspects could also be modified/controlled in future studies, such as recording the initial social interaction operant repertoire (social skills, for instance), in order to verify whether the intervention contributed to broadening this repertoire; the use of other ex- perimental designs, such as a multiple baseline design among participants as this may increase control of external variables. Studies like these could, in the future, contribute to more efficacious interventions, with importance also being given to possible analysis of sense of presence in each scenario, as well as the impact of interactive resources that are more realistic for the individuals involved, such as gloves that are touch sensitive in relation to virtual stimuli. Development of VR technology is fully underway and it is characteristic of psychology sciences to incorporate the formal evaluation of new technologies into studies in this field in order to measure the impact of their use as alternative therapeutic resources. These resources may be alternatives to techniques currently used, such as exposure with response prevention and systematic desensitization (Barbosa, 2013; Barbosa \& Lima, 2014). In addition, VR can contribute as a useful context for promoting spoken therapy along with other resources already in use.

\section{References}

American Psychiatric Association. (2013). Diagnostic and statistical manual of mental disorders ( $5^{\text {th }}$ ed.). Arlington, VA: American Psychiatric Publishing.

Anderson, P. L., Price, M., Edwards, S. M., Obasaju, M. A., Schmertz, S. K., Zimand, E., \& Calamaras, M. R. (2013). Virtual reality exposure therapy for social anxiety disorder: A randomized controlled trial. Journal of Consulting and Clinical Psychology, 81(5), 751-760. doi: 10.1037/ a0033559

Barbosa, J. I. C. (2013). Terapia por realidade virtual (VRET): Uma leitura analítico-comportamental. Boletim Contexto - ABPMC, 38, 113-132. Retrieved from http://abpmc.org.br/arquivos/publicacoes/1405369702866768607035.pdf

Barbosa, J. I. C., \& Lima, L. S. (2014). Terapia de exposição ao estímulo fóbico com o uso de Realidade Virtual: Uma revisão bibliográfica. In N. B. Borges, L. F. G. Aureliano, \& J. L. Leonardi (Eds.), Comportamento em Foco (Vol. 4, pp. 73-82). São Paulo, SP: ABPMC. Retrieved from http://abpmc.org.br/arquivos/publicacoes/14162 2281567a933aae65d.pdf 
Beidel, D. C., Alfano, C. A., Kofler, M. J., Rao, P. A., Scharfstein, L., \& Wong Sarver, N. (2014). The impact of social skills training for social anxiety disorder: A randomized controlled trial. Journal of Anxiety Disorders, 28, 908-918. doi: 10.1016/j.janxdis.2014.1009.1016

Cunha, J. A. (2001). Manual da versão em português das Escalas Beck. São Paulo, SP: Casa do Psicólogo.

Del Prette, Z. A. P., \& Del Prette, A. (2008). Significância clínica e mudança confiável na avaliação de intervenções psicológicas. Psicologia: Teoria e Pesquisa, 24(4), 497-505. doi: 10.1590/ S0102-37722008000400013

Harris, S. R., Kemmerling, R. L., \& North, M. M. (2002). Brief virtual reality therapy for public speaking anxiety. Cyberpsychology \& Behavior, 5(6), 543-550. doi: $10.1089 / 109493102321018187$

Hartanto, D., Kampman, I. L., Morina, N., Emmelkamp, P. G. M., Neerincx, M. A., \& Brinkman, W.-P. (2014). Controlling social stress in virtual reality environments. PLOS ONE 9(3). e92804. doi: 10.1371/journal.pone.0092804

Heijden, N. T., \& Brinkman, W. P. (2011). Design and evaluation of a virtual reality exposure therapy system with automatic free speech interaction. Journal of CyberTherapy \& Rehabilitation, 4(1), 41-56. Retrieved from http://repository. tudelft.nl/islandora/object/uuid:924c076e-5bf34c45-b714-94d391cf9020?collection=research

Holt, C. S., Heimberg, R. G., Hope, D. A., \& Liebowitz, M. R. (1992). Situational domains of social phobia. Journal of Anxiety Disorders, 6(1), 63 77. doi: 10.1016/0887-6185(92)90027-5

Kampmann, I. L., Emmelkamp, P. M., Hartanto, D., Brinkman, W. P., Zijlstra, B. J., \& Morina, N. (2016). Exposure to virtual social interactions in the treatment of social anxiety disorder: A randomized controlled trial. Behaviour Research and Therapy, 77, 147-56. doi: 10.1016/j. brat.2015.1012.1016

Klinger, E., Bouchard, S., Legeron, P., Roy, S., Lauer, F., Chemin, I., \& Nugues, P. (2005). Virtual reality therapy versus cognitive behavior therapy for social phobia: A preliminary controlled study. Cyberpsychology \& Behavior, 8(1), 7688. doi: 10.1089/cpb.2005.8.76

Leonardi, J. L., Borges, N. B., \& Cassas, F. A. (2012). Avaliação funcional como ferramenta norteado- ra da prática clínica. In N. B. Borges \& F. A. Cassas (Eds.), Clínica analítico-comportamental: Aspectos teóricos e práticos (pp. 105-109). Porto Alegre, RS: Artmed.

Morina, N., Brinkman, W-P., Hartanto, D., \& Emmelkamp, P. M. G. (2014). Sense of presence and anxiety during virtual social interactions between a human and virtual humans. PeerJ 2:e337. doi: 10.7717/peerj.337

Nobile, G. F. G., Garcia, V. A., \& Bolsoni-Silva, A. T. (2017). Análise sequencial dos comportamentos do terapeuta em psicoterapia com universitários com transtorno de ansiedade social. Perspectivas em Análise do Comportamento, 8, 16-31. doi: 10.18761/pac.2016.030

Osório, F. L., Crippa, J. A. S., \& Loureiro, S. R. (2009). Validação transcultural da versão para o português do Brasil do Social Phobia Inventory (SPIN): Estudo dos itens e da consistência interna. Revista Brasileira de Psiquiatria, 31(1), 25 29. doi: 10.1590/S1516-44462008005000018

Owens, M. E., \& Beidel, D. C. (2015). Can virtual reality effectively elicit distress associated with social anxiety disorder? Journal of Psychopathology and Behavioral Assessment. 37, 296305. doi: 10.1007/s10862-014-9454-x

Powers, M. B., Briceno, N. F., Gresham, R., Jouriles, E. N., Emmelkamp, P. M. G., \& Smits, J. A. J. (2013). Do conversations with virtual avatars increase feelings of social anxiety? Journal of Anxiety Disorders, 27(4), 398-403. doi: 10.1016/j.janxdis.2013.03.003

Price, M., Mehta, N., Tone, E. B., \& Anderson, P. L. (2011). Does engagement with exposure yield better outcomes? Components of presence as a predictor of treatment response for virtual reality exposure therapy for social phobia. Journal of Anxiety Disorders, 25(6), 763-770. doi: 10.1016/j.janxdis.2011.03.004

Qu, C., Brinkman, W., Ling, Y., Wiggers, P., \& Heynderickx, I. (2014). Conversation with a virtual human: Synthetic emotions and human responses. Computers in Human Behavior, 34, 58-68. doi: 10.1016/j.chb.2014.01.033

Rocha, J. F., Bolsoni-Silva, A. T., \& Verdu, A. C. M. A. (2012). O uso do treino de habilidades sociais em pessoas com fobia social na terapia comportamental. Perspectivas em Análise do Comportamento, 3(1), 38-56. 
Roy, S., Klinger, E., Légeron, P., Lauer, F., Chemin, I., \& Nugues, P. (2003). Definition of a VRBased Protocol to treat social phobia. Cyberpsychology \& Behavior, 6(4), 411-420. doi: 10.1089/109493103322278808

Sampaio, N. S. de P., \& Bueno, G. N. (2011). Manejo da fobia à exposição oral: Estratégias comportamentais como agentes de controle. In C. V. B. B. Pessôa, C. E. Costa, \& M. F. Benvenuti (Eds.), Comportamento em Foco (Vol. 1, pp. 583-598). São Paulo, SP: ABPMC.

Silvares, E. F. D. M., \& Meyer, S. B. (2000). Análise funcional da fobia social em uma concepção behaviorista radical. Revista de Psiquiatria Clínica, 27(6), 329-334.

Slater, M., Pertaub, D. P., Barker, C., \& Clark, D. M. (2006). An experimental study on fear of public speaking using a virtual environment. $C y$ berpsychology \& Behavior, 9(5), 627-633. doi: 10.1089/cpb.2006.9.627

Stevens, S., Peters, A., Abraham, A., \& Hermann, C. (2014). Enhanced avoidance behavior in social anxiety: Evidence from a probabilistic learning task. Journal of Behavior Therapy and Experimental Psychiatry, 45, 39-45. doi: 10.1016/j. jbtep.2013.1007.1007

Sturmey, P. (1996). Functional analysis in clinical psychology. Chichester, UK: John Wiley \& Sons.

Wallach, H. S., Safir, M. P., \& Bar-Zvi, M. (2011). Virtual reality exposure versus cognitive restructuring for treatment of public speaking anxiety: A pilot study. Israel Journal of Psychiatry
\& Related Sciences 48(2), 91-97. doi: 22120443

Wiederhold, B. K., Jang, D. P., Kim, S. I., \& Wiederhold, M. D. (2002). Physiological monitoring as an objective tool in virtual reality therapy. Cyberpsychology \& Behavior, 5(1), 77-82. doi: $10.1089 / 109493102753685908$

Wolpe, J. (1978). Prática da terapia comportamental ( $2^{\text {nd }}$ ed., W. G. Clark Jr., Trans.). São Paulo, SP: Brasiliense. (Original work published in 1973)

Zacarin, M. R. J., Borloti, E. Santos, A., Perandré, Y. H. T., Melo, C. M. \& Haydu, V. B. (2017). Senso de presença: Proposta de uma definição analítico-comportamental. Acta Comportamentalia. 25(2), 249-263.

Zamignani, D. R., \& Banaco, R. A. (2005). Um panorama analítico-comportamental sobre os transtornos de ansiedade. Revista Brasileira de Terapia Comportamental e Cognitiva, 7, 77-92. Retrieved from http://www.usp.br/rbtcc/index.php/RBTCC/article/view/44/33
Received: 25/10/2016

$1^{\text {st }}$ revision: $29 / 04 / 2017$

$2^{\text {nd }}$ revision: $23 / 05 / 2017$

Accepted: 23/05/2017

(cc)BY (C) The Author(s), 2018. Open Access. This article is distributed under the terms of the Creative Commons Attribution 4.0 International License (http://creativecommons.org/licenses/by/4.0/), which permits unrestricted use, distribution, and reproduction in any medium, provided you give appropriate credit to the original author(s) and the source, provide a link to the Creative Commons license, and indicate if changes were made. 